\title{
PENGARUH EFEK LEVERAGE SEBAGAI PEMODERASI TERHADAP HUBUNGAN ANTARA RETURN ON EQUITY (ROE) DAN STRUKTUR MODAL
}

\author{
Sherly Fristylia Ramdini ${ }^{1}$, Francis Hutabarat ${ }^{* 2}$ \\ 1,2 Program Studi Akuntansi Fakultas Ekonomi Universitas Advent Indonesia \\ e-mail: sherlyfristylia06@gmail.com¹, fmhutabarat@ unai.edu ${ }^{* 2}$
}

\section{* Corresponding Author}

\begin{abstract}
Research that can be done to study the relationship of return on equity to capital structure with Leverage dieminten period 2017-2018 Property \& Real Estate Subsector on the IDX. Secondary data retrieval is based on 14 units from the Property \& Real Estate sub-sector using Purposive Sampling techniques and related annual reports with the following company codes APLN, ASRI, KIJA, GAMA, BSDE, BKSL, CTRA, MYRX, SMDM, SMRA, LPCK, LPKR, BEST, and FATHER. The results of this study indicate that leverage has a good or positive relationship with the capital structure in the Real Estate and Property emintent for the period 2017-2018. While ROE does not have a relationship related to the Capital Structure of the emintent in Real Estate and Property listed on the IDX for the period 2017-2018
\end{abstract}

Keywords: Return on Equity, Leverage, Capital Structure

\section{Pendahuluan}

Era globalisasi yang menjadikan perkembangan teknologi sebagai suatu acuan dan juga dapat mengakibatkan suatu persaingan yang cukup kompetitif didunia bisnis. Sehingga mengharuskan perusahaan untuk dapat bersaing sacara kreatif serta inovasi dalam menciptakan strategi yang dapat menunjang keunggulan dan eksistensi perusahaan. Pada masa ini struktur modal menjadi perkembangan setiap perusahaan yang diikuti dengan menggunakan prospek modal yang besar. Jika suatu perusahaan dapat menentukan struktur modal, maka perusahaan akan menghasilkan suatu dampak pada tunggakan jangka panjang serta juga jangka pendek. Sehingga perusahaan dapat menilai tanggungan anggarannya.

Maka dari itu fenomena yang terkait dengan struktur modal yang dilansir oleh Avanty Nurdiana (2020) artikel yang terdapat pada situs berita kontan.co.id (02/05/2020) dengan kasus yang terjadi oleh perusahaan OCBC NISP yang memiliki hutang berupa obligasi berkelanjutan NISP III tahap I/2018 seri B sebesar 3 miliar. Dan perusahaan akan memenuhi kewajiban tersebut menggunakan dana internal. Dan pada per 29 Februari 2020, NISP membukukan kas dan penempatan di Bank Indonesia dengan jumlah yang memadai sebesar Rp 8,6 triliun.
Hutang yang dimiliki NISP sudah mencapai peringkat tertinggi yang pernah dicapai. Sepanjang kuartal I2020, NISP meraih laba bersih Rp 791 miliar atau tumbuh $3,4 \%$ secara tahunan. Sementara aset OCBC NISP tercatat tumbuh 7,8\% menjadi Rp 191,5 triliun. Adapun penyaluran kredit tumbuh 5,4\% menjadi Rp 123,9 triliun. Pertumbuhan kredit tersebut juga terjaganya kualitas kredit dengan rasio NPL gross $1,8 \%$, dan NPL nett $0,9 \%$. Sedangkan dana pihak ketiga tumbuh 5,2\% menjadi Rp 137,4 triliun.

Maka dapat disimpulkan terkait fenomena yang dialami oleh OCBC dalam upaya untuk memenuhi segala kewajiban yang dimiliki, maka dapat ditarik kesimpulan bahwa OCBC dalam upaya untuk memenuhi kewajiban dengan dana internal yang dimiliki. Dan hal ini merupakan strategi perusahaan dalam mengelola akan struktur modal dengan perimbangan antara total utang dengan dana internal.

Setiap investor akan melakukan pemilihan yang akan dilihat salah satunya jenis saham, serta dapat diartikan bahwa pengembalian ekuitas merupakan alat untuk mengukur suatu perusahaan dalam memperoleh laba. Hal ini pun dapat memiliki keterkaitan dengan banyaknya hutang. Jika pesentase hutang semakin besar maka pengembalian ekuitas atau yang biasa disebut dengan Return on Equity pun akan semakin 
meningkat (Sartono, 2001). Sehingga pengembalian ekuitas akan dikatakan baik, jika perolehan laba yang dihasilkan akan menjadi lebih meningkat.

Menurut Kasmir (2015), leverage dapat dilihat dari harta perusahaan yang berkaitan dengan hutang dengan perbandingan akan harta priadi. Solvabilitas dapat dinilai berpengaruh kepada struktur modal perusahaan. Dan pada solvabilitas atau leverage merupakan suatu elemen dengan penggunaannya agar dapat memantau kesanggupan dalam memenuhi hutang.

Dapat dikatakan dalam penelitian ini, memiliki sasaran untuk menganalisa pengaruh Return on Equity terhadap Struktur Modal dengan menggunakan mediasi Leverage. Yang tercatat di eminten subsektor Real Estate \& Property dalam hal ini digunakan agar dapat melihat bagaimana kondisi keuangan perusahaan dan juga mencari pengaruh dari unsur-unsur terkait dengan struktur modal tersebut.

\section{Kerangka Teoritis \\ Return on Equity}

Pengembalian ekuitas dapat dikatakan merupakan suatu alat dalam melaksanakan pengukuran dari Net Income After Tax melalui modal pribadi, yang diartikan menurut Kasmir (2015) sedangkan berdasarkan Syamsudin (2013), pengembalian ekuitas atau dalam bahasa inggris yaitu return on equity (ROE) merupakan sebuah alat ukur yang berasal da dilihat dari pendapatan pemilik dan tentu juga bagi seluruh pemegang saham dalam suatu organisasi atau perusahaan. Terkait dengan untuk bank, modal dapat juga menjadi peran penting pada dunia bisnis perbankan, tapi modal disini hanya menjadi komponen kecil dari modal bank. Hal ini memiliki 2 bagian yaitu Primary capital yang biasa disebut dengan modal pribadi dan secondary capital atau yang biasa disebut juga dengan tambahan modal.

Pengembalian ekuitas biasa ditunjukkan oleh tingkat akuntansi pengembalian penanaman modal bagi investor dilihat berdasarkan keuntungan bersih terhadap ekuitas umum. (Keown, 2005). Yang berarti bahwa suatu perbandingan antara laba dengan modal yang menghasilkan keuntungan, merupakan aspek untuk mengetahui persentase dalam pengembalian kepada pemegang saham. Dan laba bersih menjadi aspek penting dalam pengukuran persentase pengembalian.
Modal pribadi dapat dikategorikan serupa dengan modal yang diterima secara pribadi yaitu merupakan modal golongan serupa dengan senior capital yaitu rancangan dana diperoleh berdasarkan saham preferen beserta obligasi. Hal ini tak menjadi golongan anggaran dana atau modal, sekalipun ttidak masuk kedalam golongan dalam perbankan tetap menjadi aspek yang besar dan berpengaruh terpaut dengan harta bank yang dibayarkan dari simpanan masyarakat (Pandia, 2012).

$$
\text { Return on Equity }(R O E)=\frac{\text { earning after taxes }}{\text { total equity }}
$$

Menurut Irwati (2006) menjelaskan mengenai rumus $R O E$ yang besar, hal ini akan berkaitan dengan oragnisasi dalam menentukan prospek keuntungan dalam menghasilkan keuntungan tertinggi terutama bagi para investor. Sehingga bisa dijelaskan pengembalian ekuitas atau $R O E$ ini memiliki relevansi kepada investor yang menanamkan modalnya, sebab dapat memantulkan kesempatan pada tingat keuntungan yang dapat memperoleh laba.

\section{Leverage}

Menurut Hery (2016) rasio leverage merupakan suatu elemen dalam melakukan pengukuran dari kapasitas organisasi ataupun perusahaan dengan maksud upaya pemenuhan terhadap seluruh hutang atau liabilities maupun tunggakan jangka panjang serta jangka pendek. Dengan kata lain mampu dikatakn rasio tersebut memperlihatkan kesanggupan untuk memenuhi setiap kewajiban moneter. Pada aktivitas bidang usaha, eminten kadang kala bertemu terhadap pengeluaran dana bersifat permanen, hal ini memuat berbagai ancaman. Bersangkutan kepada manajemenpatut memahami perihal leverage. Hal ini memuat akan anggaran secara permanen, dimana dapat memanifestasikan kelebihan yang cukup baik, dan dapat diartikan juga sebagai alat untuk melakukan pengilustrasian terhadap kemampuan dalam penggunaan asset yang memiliki kewajiban tetap atau bias disebut juga dengan fixed cost asstes dalam memenuhi pendapatan terhadap pemilik perusahaan, hal ini merukapan pengertian menurut (Syamsudin, 2013).

Menurut Sudana (2011) terdapat beberapa aspek untuk dapat mengukur pelaksanaan kewajiban pada 
pembelanjaan suatu organisasi dan juga perushaan. Dan hal ini mampu diukur menggunakan cara seperti:

a) Cash Coverage

Cash Coverage $=\frac{E B I T+\text { Depreciation }}{\text { Interest }}$

Cash coverage mampu untuk menafsirkan kapasitas dengan menggunakan alat ukur dengan melihat laba sebelum bunga dan pajak (EBIT), ketika cash coveage memperlihatkan kenaikan terhadap kapasitas perusahaan dalam melunasi semua bunga dan hal tersebut pun mempengaruhi persentase terhadap bunga tersebut. Sehingga prospek dalam mendapatkan pinjaman yang cukup besar.

b) Debt Ratio

$$
\text { Debt Ratio }=\frac{\text { Total Debt }}{\text { Total Asset }}
$$

Hal ini dapat menmperkirakan perimbangan dana yang didasarkan dengan semua hutang sebagi upaya dalam mendukung pemenuhan biaya perusahaan. Ketika debt ratio meningkat maka pengalokasian hutang untuk memenuhi penanaman modal terhadap asset dan hal tersebut juga menjadi aspek penting untuk perusahaan memiliki ancaman terhadap keuangan perusahaan. risiko keuangan perusahaan meningkat dan sebaliknya.

c) Times interest earned

$$
\text { Time Interest Earned Ratio }=\frac{E B I T}{\text { Interest }}
$$

Ratio berikut merupakan aspek dalam upaya pengukuran kesanggupan dari perusahaan dalam melunasi semua tanggung jawab yang terdiri dari bunga dan yang menggunakan laba sebekum bunga dan pajak. Ketika time interest earned ratio meningkat maka kesempatan dan juga kesanggupan perusahaan akan merima tambahan pinjaman akan ikut berpengaruh sehingga menjadi meningkat. d) Long-term debt to equity

$$
\text { Long }- \text { term Debt Equity }=\frac{\text { Long }- \text { term debt }}{\text { Equity }}
$$

Long-term debt rasio berfungsi untuk dapat melihat ukuran perkembangan tinggi atau rendahnya pemanfaatan hutang jangka panjang. Dan juga perlu dilakuka analisis terhadap datadata keuangan setiap tahun untuk membantu memperbaiki akan semua kekurangan yang ada pada laporan ditahun sebelum. Jika rasio semakin meningkat maka dapat menyebabkan ancaman terhadap keuangan perusahaan yang akan semakin meningkat juga.

\section{Struktur Modal}

Struktur modal dapat diartikan menurut Agus Sartono (2008) ialah pertimbangan dari tunggakan jangka panjang serta jangka pendek, dengan memiliki sifat yang permanen. Dan beberapa aspek yang mempengaruhi struktur laporan keuangan merupakan perbandingan dari jumlah hutang dengan semua modal yang dimiliki oleh pribadi.

Pada ketetapan yang terkait dengan struktur modal atau capital structure dan hal ini memilki keterkaitan dengan ancaman maupun resiko yang akan diterima oleh semua investor, yang diukur dari tinggi dan rendahnya suatu pencapaian perusahaan (Houston dan Brigham, 2001). Terkait dengan penjelasan tersebut dapat mendukung akan kelangsungan dari kemajuan perusahaan.

Ada beberapa faktor yang berpengaruh kepada struktur modal, pengertian menurut Weston dan Brigham (2011), terdapat unsur-unsur yang akan melihat pengaruh terhadap struktur modal dengan:

1. Profitabilitas

Sartono (2001) melihat mengenai profitabilitas ini dilihat dari kesanggupan setiap perusahaan dalam menghasilkan keuntungan dalam berupa laba dari hasil penjualan.

2. Struktur Saingan

Dalam upaya untuk menghasilkan keuntungan serta persentase penjualan memiliki keterampilan dalam pengoperasian dalam hutang yang beredar pada perusahaan. Sehingga margin laba memiliki kepenting dalam kestabilan dan juga memiliki kepentingan yang sama dengan stabilitas dari 
pernjuala. Yang dapat disimpulkan, bahwa semua organisasi yang baru terbentuk terjun kedalam industry, serta kapasitas dalam persaingan yang beredar pada dunia era globalisasi saat ini.

3. Stabilitas Penjualan

Kestabilan dalam penjualan serta utang memiliki hubungan satu sama lain. Terkait dengan kestabilan akan lebih meningkat terkait penjualan dan upaya menghasilkan laba. Setiap oraganisasi dapat mengaitkan semua kewajiban terkait dengan ancaman yang kecil dibandingkan pada saat penjualan dan keuntungan menjadi menurun, sehingga membuat perusahaan atau organisasi menjadi terhambat dalam melunasi semua hutang.

4. Struktur Aktiva

Dalam hal ini asset atau harta suatu perusahaan memiliki pengaruh terhadap sumber pembelanjaan dangan bermacam strategi. Dampak terkait asset tetap atau fixed asset yang bermassa lebih panjang, dan yang terpenting dilihat kepada output yang menjadi acuannya.

5. Sikap Manajemen

Membahas mengenai perilaku manajemen, hal ini juga menjadi suatu acuan terpenting dalam kelangsungan aktivitas suatu organisasi maupun perusahaan. Dikarenakan peranan seorang manajemn akan mengarahkan kepada setiap akses pembelian kebutuhan, atau pun terkait kedalam hal pengambilan suatu keputusan yang mungkin akan menentukan tahap akhir yang diterima oleh perusahaan.

6. Sikap Pemberi Pinjaman

Jika membahas semua aspek yang terkait dengan leverage. Saat ini hal yang tak kalah penting dengan aspek-aspke sebelumnya, perilaku pemberian pinjaman pun memiliki hal yang penting. Dikarenakan hal ini sering terlepas dari pandangan disetiap perusahaan, sehingga dapat menentukan faktor dari struktur modal.

Pada penelitian yang terkait dengan struktur modal dan hal ini diimplementasikan dengan DER seperti yang dipaparkan oleh Jaros (2015) dan Githira (2015). Adapun DER dilihat dengan rumus:

$$
D E R=\frac{\text { Total Debt }}{\text { Total Equity }}
$$

\section{Metode Penelitian}

Penelitian dilakukan dalam upaya untuk mencapai serta menerapkan suatu tujuan dalam pengembangan ilmu pengetahuan. Penelitian bertujuan untuk mencakup masalah dan pemecah masalah yang terjadi.

Penelitian yang dilakukan menggunakan eminten yang tertera pada IDX menggunakan data sekunder, berasal dari eminten melalui situs resmi Bursa Efek Indonesia pada tahun periode 2017-2018 yang mempublikasikan laporan keuangan.

Pendekatan atas eksplorasi dari teknik pengambilan sampel purposive. Populasi bersumber dari 14 eminten dalam tahun 2017-2018 pada subsektor Real Estate \& Property di Bursa Efek Indonsia.

Pengambilan sempel dilakukan berdasarkan kriteria yaitu:

1. Eminten yang bersumber dari subsektor Property \& Real Estate yang terdapat pada Indonesia Stock Exchange pada term 2017-2018.

2. Eminten menerbitkan Annual Report secara beruntun dari tahun 2017 - 2018 .

3. Eminten yang menyandang data laporan keuangan berkaitan terhadap komponen yang akan dicermati seperti, Return on Equity dan Leverage.

\section{Variabel Independen}

Variable independen pada eksplorasi merupakan pengembalian modal (ROE) untuk memvisualisasikan suatu kesetaraan terhadap Earning Before Interest Tax dapat dirumuskan sebagai berikut:

$$
R O E=\frac{\text { earning after taxes }}{\text { total equity }}
$$

\section{Varibel Dependen}

Ada variable ini memaparkan mengenai struktur modal yang menjadi alat ukur menggunakan rumus DER, berfungsi sebagai patokan terhadap sumber dana perusahaan yang berasal dari hutang. Dengan dirumuskan sebagai berikut:

\section{Variabel Mediasi}

$$
D E R=\frac{\text { Total Debt }}{\text { Total Equity }}
$$

Variable mediasi pada penelitian ini ialah Leverage yang merupakan. Dalam variable ini memperlihatkan kapasitas dalam menyanggupi 
kewajiban finansialnya, pada hutang dengan ukuran panjang dan pendeknya massa yang berjalan.

\section{Hasil Penelitian dan Pembahasan Koefisien Determinasi}

Tabel 2. Koe. Der

\begin{tabular}{|c|c|c|c|c|}
\hline Mdl & $\mathrm{R}$ & $\mathrm{R}^{2}$ & R Sq. Change & Std. Err. Estim \\
\hline 1 & $.143^{\mathrm{a}}$ & .021 & .021 & .44513 \\
\hline 2 & $.983^{\mathrm{b}}$ & .966 & .945 & .08432 \\
\hline
\end{tabular}

a. Predic. : (Constant), ROE

b. Predic. : (Constant), ROE, DAR

Pada tabel diatas menperlihatkan bahwa pada model nilai R-Square adalah sebesar .021 yang berarti kontribusi ROE terhadap perubahan pada Struktur Modal adalah sebesar $2.1 \%$.

Terkait model 2, didapati bahwa dengan mediasi leverage maka didapati kontribusi ROE dan leverage terhadap perubahan pada Struktur Modal menjadi sebesar $96.6 \%$ Dan didapati perubahan dalam taksiran R-Sq.change sebesar .945 / 94.5\%.

Significant Test

Tabel 3. Significant Test

\begin{tabular}{|l|l|r|r|r|r|r|}
\hline \multicolumn{2}{|c|}{ Mdl } & $\begin{array}{r}\text { Sum.of. } \\
\text { Sq }\end{array}$ & \multicolumn{1}{c|}{ df } & Mean. Sq & F & Sig. \\
\hline \multirow{2}{*}{1} & Regression & 0.108 & 1 & 0.108 & .544 & $.467^{\mathrm{a}}$ \\
\cline { 2 - 7 } & Residual & 5.152 & 26 & .198 & & \\
\cline { 2 - 7 } & Total & 5.259 & 27 & & & \\
\hline \multirow{2}{*}{2} & Regression & 5.082 & 2 & 2.541 & 357.335 & $.000^{\mathrm{b}}$ \\
\cline { 2 - 7 } & Residual & .178 & 25 & .007 & & \\
\cline { 2 - 7 } & Total & 5.259 & 27 & & & \\
\hline
\end{tabular}

a. Predic. : (Constant), ROE

b. Predic. : (Constant), ROE, DAR

c. Dep. Var. : DER

Hasil uji signifikan menunjukkan bahwa pada model 1 tidak berpengaruh signifikan terhadap pengembalian ekuitas (ROE) terhadap Capital Structure. Hasi uji memperlihatkani taksiran dari Ftest sebesar .544

Serta taksiran significant .467 pada $\alpha=0.05$ atau 5\%. Sedangkan pada model 2, didapati bahwa dengan adanya mediasi Leverage maka didapati pengaruh ROE, Leverage terhadap Struktur Modal adalah significant dengan tingkat signifikan 0.000 pada $\alpha=0.05$ atau $5 \%$ dengan F-test 357.335 .

\section{Regression}

Tabel 4. Regression

\begin{tabular}{|c|c|c|c|c|c|c|}
\hline & \multirow[b]{2}{*}{ Mdl } & \multicolumn{2}{|c|}{$\begin{array}{c}\text { Unstand. } \\
\text { Coefficients }\end{array}$} & \multirow{2}{*}{$\begin{array}{c}\begin{array}{c}\text { Stand. } \\
\text { Coefficients }\end{array} \\
\text { Beta }\end{array}$} & \multirow[b]{2}{*}{$\mathrm{t}$} & \multirow[b]{2}{*}{ Sig. } \\
\hline & & B & Std. Err & & & \\
\hline \multirow[t]{2}{*}{1} & (Cons) & .713 & .119 & & 6.013 & .000 \\
\hline & ROE & .891 & 1.207 & .143 & .738 & .467 \\
\hline \multirow[t]{3}{*}{2} & (Cons) & -.506 & .051 & & -9.862 & .000 \\
\hline & ROE & .324 & .230 & .052 & 1.412 & .170 \\
\hline & DAR & 3.123 & .118 & .977 & 26.448 & .000 \\
\hline
\end{tabular}

a. Dependent Variable: DER

Hasil uji signifikan menunjukkan bahwa diantara variable independent maka terlihat bahwa pada model 1 memiliki pengaruh tidak relevan pada variable pengembalian ekuitas (ROE) dengan Capital Structure. Serta taksiran signifikan 0.467 pada level signifikan 5\%.

Sedangkan pada model 2, didapati dengan adanya mediasi Leverage (DAR), didapati bahwa ROE dan Struktur Modal (DER) tetap memiliki pengaruh yang tidak signifikan yaitu 0.170 pada level signifikan 5\%.

Dan terkait Leverage (DAR) dan Struktur Modal didapati adanya pengaruh yang signifikan dengan level signifikan 0.000 pada level signifikan 5\%. Dengan demikian keberadaan Leverage (DAR) sepenuhnya memediasi pengaruh ROE dan Struktur Modal (DER).

\section{Hipotesis Penelitian}

\section{H1: ROE dan Struktur Modal (DER)}

Pada penelitian ini didapati bahwa hipotesa 1 memiliki pernyataan terdapat pengaruh yang signifikan antara ROE dan Struktur Modal. ROE merupakan alat menaksirkan kapasitas eminten dalam memperoleh keuntungan.

Capital structure merupakan rasio untuk melihat perbandingan antara sumber dana perusahaan 
yang bersumber dari ekuitas dan sumber dana bersumber dari hutang. Hasil penelitian menunjukkan bahwa tidak ada dampak signifikan terhadap ROE dan Capital Stucture.

Pengkajian ini didukung oleh observasi terdahulu dimana tidak berpengaruh signifikan terhadap ROE dan struktur modal oleh Ningsih (2012), Mohamed M. Khalifa Tailab (2014) dan Mega Junita (2014).

Namun hasil ini memiliki hal yang bertolak belakang dengan penelitian lain yang mengatakan ada pengaruh yang signifikan terhadap ROE dan Struktur Modal Lida Simanjuntak (2012), M. Shofiyuddin (2015) dan Putri Ismaida (2016)

\section{H2: Leverage (DAR) dan Struktur Modal (DER)}

Pada penelitian ini didapati bahwa hipotesa 2 memiliki pernyataan ada pengaruh yang signifikan antara Leverage dan Struktur Modal. Leverage rasio memiliki sifat untuk melakukan pengukuran persentase hutang perusahaan.

Struktur modal merupakan rasio yang melihat perbandingan antara sumber dana perusahaan yang bersumber dari ekuitas dan sumber dana bersumber dari hutang. Hasil penelitian menunjukkan bahwa ada dampak signifikan terhadap Leverage dan Capital Stucture.

Pengkajian ini didukung oleh observasi terdahulu ada pengaruh yang signifikan antara Leverage dan struktur modal oleh Agustiawan (2009), Rahmat (2010) dan Putri Ismaida (2016).

Namun hasil ini memiliki hal yang bertolak belakang dengan penelitian lain yang mengatakan tidak berpengaruh signifikan terhadap Leverage dan Capital Structure Wardani (2011), Ilham (2013) dan M. Shofiyuddin (2015).

\section{Kesimpulan dan Saran}

Berdasarkan observasi yang terjadi dan telah teruji dalam pembahasan terdahulu, maka dapat ditarik kesimpulan akan penelitian ini dengan merujuk pada perumusan masalah, yang diambil dari emintenreal estate dan property yang tertera pada Indonesia Stock Exchange dalam fase 2017-2018. Pengembalian ekuitas tak berpengaruh signifikan dengan capital structure, namun dengan adanya metode mediasi Leverage maka didapati impak signifikan antara capital structure.
Pada hasil observasi in, maka saran yang dapat diberikan untuk eksplorasi tersebut dikarenakan masih perlu untuk dilakukan pengujian kembali, jumlah sampel dan tahun yang berbeda maka akan membuat hasil intepretasi yang berbeda juga. Dan bagi investor agar dapat lebih memperhatikan dikarenakan Return on Euity yang berfungsi untuk menghasilkan laba tidak memiliki pengaruh terhadap struktur modal dalam suatu perusahaan, namun perusahaan memiliki kemampuan perusahaan dapat melengkapi semua tanggung jawab dalam dari tunggakan jangka panjang serta jangka pendek, sehingga dapat mempengaruhi suatu hal yang berguna terhadap struktur modal.

\section{Daftar Pustaka}

Agustiawan, (2009). Analisis Faktor-Faktor yang Mempengaruhi Struktur Pendanaan pada Perusahaan Property dan Real Estate di Bursa Efek Indonesia. Skripsi SI. Universitas Riau

Charles. W, Githira, \& Nasieku. T. (2015). Capital Structure Determinants among Companies Quoted in Securities Exchange in East Africa. International Journal of Education \& Research. Vol. 3, No.5, May 2015. ISSN: 2411-5681. Hlm. 483-496.

Hery. (2016). Financial Ratio For Business. Jakarta: Grasindo

Houton. J, Brigham, \& Eugene F. (2001). Manajemen Keuangan. Edisi 8. Jakarta: Salemba

Houston \& Brigham. (2011). Dasar-dasar Manajemen Keuangan. Jilid 1. Jakarta: Salemba

Ilham, (2013). Pengaruh Struktur Aktiva dan Operating Leverage Terhadap Struktur Modal pada Perusahaan Makanan dan Minuman yang Terdaftar di Bursa Efek Indonesia. Jurnal Economix Volume 1 No 2

Irawati, Susan. 2006. Manajemen Keuangan. Pustaka: Bandung

Ismaida. P, \& M. Saputra. (2016). Pengaruh Pertumbuhan Penjualan, Profitabilitas, Ukura, dan Aktivitas Perusahaan Terhadap Struktur Modal pada Perusahaan Property dan Real Estate yang Terdaftar di BEI Periode 20122014. Jurnal Ilmiah Mahasiswa Ekonomi Akuntansi, Vol. 1 No. 1, Hal 221-229

Jaros, Jaroslav, \& Viera Bartosova. 2015. $4^{\text {th }}$ World Conference on Business, Economics and Management, WCBEM To The Capital 
Structure Choice: Miller and Modigliani Model. Procedia economics and Finance, Vol. 26. Hlm. 351-358.

Junita. M, Nasir. A, \& Ilham. E. (2014). Pengaruh profitabilitas, pertumbuhan aset, operating leverage, dan ukuran perusahaan terhadap struktur modal studi empiris pada perusahaan food and beverages yang terdaftar di bursa efek indonesia periode 2010-2012. JOM FEKON Vol. 1 No. 2

Kasmir. (2015). Analisis Laporan Keuangan. Edisi Pertama. Cetakan 5. Rajawali Pers.Jakarta

Keown. (2005). Financial Management. Edition 10. New Jersey: Pearson Education Inc

Lukman. S. (2013). Manajemen Keuangan Perusahaan: Konsep Aplikasi dalam Perencanaan, dan Pengambilan Keputusan. Jakarta : Rajawali Pers

Nurdiana, A. (2020). OCBC NISP (NISP) Memiliki Utang Jatuh Tempo pada 6 Juli. Diambil dari: https://keuangan.kontan.co.id/news/ocbcnispnis memiliki-utang-jatuh-tempo-pada-6-juli

Pandia, F. (2012). Manajemen Dana dan kesehatan Bank. Jakarta: Rineka Cipta

Rahmat, \& Handayani. E. (2010). Pengaruh Struktur Aset, Profitabilitas, Operating Leverage, dan tingkat pertumbuhan terhadap struktur modal pada perusahaan Real Estate dan Property yang terdaftar di BEI. Skripsi S1. Universitas Airlangga.

Sartono. A, (2008). Manajemen Keuangan Teori dan Aplikasi; BPFE. Cetakan 2. Yogyakarta

Sartono, R. A. 2001. Manajemen Keuangan Teori dan Aplikasi. Edisi 4. BPFE. Yogyakarta.

Setya, Y. N. (2012). Pengaruh Profitabilitas, Struktur Aktiva, Ukuran Perusahaan, Growth, Oppurtunity, dan Operating Leverage Terhadap Struktur Modal Pada Perusahaan Property yang Terdaftar di BEI periode 2006-2010. Skripsi S1. Universitas Negeri Yogyakarta.

Shofiyuddin. M (2015). Analisi Pengaruh Leverage Operasi, Pertumbuhan Aset dan Profitabilitas Terhadap Struktur Modal Studi Kasus Pada Perusahaan Food and Beverages yang Terdaftar di BEI. Jurnal Ekonomi dan Bisnis. Volume 16. Nomor 1. ISSN: 1693-0908

Simanjuntak. L. (2012). Pengaruh Struktur Aktiva, Pertumbuhan Perusahaan, Profitabilitas, Ukuran
Perusahaan, dan Umur Perusahaan terhadap Struktur Modal pada Perusahaan Manufaktur yang terdaftar di BEI. Skripsi S1. Universitas Sumatera Utara.

Sudana, \& Made. I. (2012). Manajemen Keuangan Perusahaan Teori dan Praktik. Jakarta: Erlangga

Tailab. M. M. K (2014). The Effect of Capital Structure on Profitability of Energy American Firms. International Journal of Business and Management Invention. Volume 3 Issue 12. PP. 54-61.

Wardani, \& Kusuma. H. (2011). Pengaruh Struktur Aktiva, Ukuran Perusahaan, Profitabilitas, dan Operating Leverage Terhadap Struktur Modal Pada Perusahaan Property \& Real Estate Yang Terdaftar di BEI. Skripsi SI. Universitas Gunadrama. 